\title{
Session S3D Work in Progress: The Five Basic "Positions" of Engineering
}

\author{
Blair London ${ }^{1}$, Lisa Deyo ${ }^{2}$
}

\begin{abstract}
Classical ballet technique relies on mastery of the five basic positions of the feet. Every movement in classical ballet goes through one or more of these positions. The positions are practiced in class, used in choreography, and become second nature in performance on stage. Engineering may have a similar context. These engineering "positions" are not just the foundational coursework leading up to an engineering degree such as mathematics, chemistry, or physics. Rather, the positions are aspects of engineering that a practicing engineer routinely does to successfully perform as engineers. The engineering positions discussed are: question, analyze, team, write, and speak. We believe these positions need to be included and practiced in engineering classes because they are the essence of engineering practice and performance.
\end{abstract}

Index Terms - Ballet Positions, ABET a-k, Question, Analyze, Team, Write, Speak.

\section{INTRODUCTION}

Classical ballet is a difficult and demanding art form. It takes years of practice in class to master all the technical and artistic details. Even so, as it is with many complex art forms, classical ballet can be distilled into a few basic elements. It is from these elements that the rest of the art form develops. Beginning ballet classes stress these basic elements; however, they are reinforced in even the most advanced classes and complicated choreographies. Indeed, a key to succeeding in more challenging dance pieces is to rely on mastery of the basic elements. There are several possible groupings of classical ballet's basic elements: positions of the feet, positions of the arms, orientations of the body [1]. While the French, Italian, or Russian ballet schools have different variations on some of these basic element groupings, all of the schools have the same five positions of the feet. Everything in classical ballet goes through one or more of these five positions (Figure 1). This powerful statement is the premise of our paper. We believe this same kind of thinking can be applied to engineering.

Engineering, like classical ballet, is also difficult and complex. Our students spend years in classes mastering various aspects of engineering practice in order to work as engineering professionals for their careers. There are certain parallels between engineering and classical ballet regarding class structure and a focus on performance [2,3]. These parallels can continue by identifying the five "positions" of engineering.

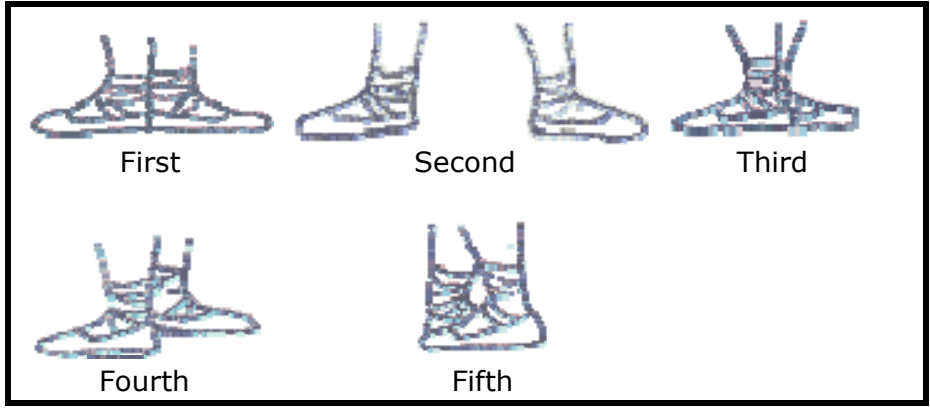

FIGURE 1

FIVE BASIC POSITIONS OF THE FEET IN CLASSICAL BALLET [4].

Five Positions: Engineering Performance

In developing our list of engineering positions, our goal was to follow the classical ballet model in three respects: (1) All movements in ballet go through one or more of the positions, (2) When attempting to master a particularly challenging choreography, going back to one or more of the basic five positions really helps, and (3) Each position has equal importance. It is precisely these three things that make the five ballet positions so useful and meaningful. The positions become second nature to ballet professionals. The five positions of engineering need to have these aspects - all engineering should go through them, they should help in the solution of particularly difficult engineering tasks, each position is equally important, and they should be second nature to engineering professionals.

\section{LISTS AND ENGINEERING}

Engineers, and educators, love lists. Our engineering fields are replete with long and short lists of topics, concepts, applications, guidelines, rules, procedures, ideas, etc. - it is one of the ways we organize information. There are several lists that can act as guides to developing five engineering positions. The most prominent list is most likely ABET a-k [5], which all programs follow. While this list is comprehensive, it is meant to guide and help evaluate engineering programs, not necessarily be a reflection of what

\footnotetext{
${ }^{1}$ Blair London, Professor, Materials Engineering Department, California Polytechnic State University, San Luis Obispo, CA, blondon@calpoly.edu

${ }^{2}$ Lisa Deyo, Choreographer and Artistic Director, Deyo Dances Dance Company, San Luis Obispo, CA, lisa@deyodances.com 
an engineer does on a day-to-day basis. Other lists of "engineering basics" generally focus on technical topics. They are grouped into two levels: common core (e.g., mathematics, chemistry, physics), and specific discipline (e.g., various materials families for materials engineers). These lists are useful, but they do not fulfill the three goals of classical ballet's positions of the feet. Additionally, we are not discussing aspects or techniques of engineering problem solving [6]. We believe that a different organization and focus is required here, one transcending technical topics.

\section{Five engineering Positions}

Our list (Figure 2) is not definitive. These elements will differ between individuals and organizations. We are seeking sets of engineering activities necessary to perform engineering. These engineering "positions" need to be constantly included in our classes to better prepare our students for the profession.

\begin{tabular}{|c|c|c|}
\hline Question & Analyze & Team \\
\hline Write & Speak & \\
\hline
\end{tabular}

FIGURE 2

FIVE BASIC “POSITIONS” OF ENGINEERING.

\section{Question}

Many of us came into engineering because we were curious about the world; we had a lot of questions to ask and have answered. Somewhere along the way in years of undergraduate education, our students lose this questioning nature. This is unfortunate. The ability to formulate then pose a question is a fundamental characteristic of all engineers. Alas, many of our students do not have this ability or view it as a necessary ingredient in engineering. Making it a basic position in our classes would help alleviate this shortcoming.

\section{Analyze}

Much of engineering involves analyzing technical situations and then making a decision (e.g., looking at experimental data, determining a budget for a program). The analysis is most important. It is not sufficient simply to gather data; engineers are analyzers. A common trait among our students is that they believe gathering data is engineering. Analysis is more difficult than gathering, so students often shy away from it. We can change this situation by focusing on analysis as a basic position in class.

Closely associated with analysis are the skills of organization. Many times our engineering analysis is greatly aided by clear organization of the information. Our students experience faculty organization in courses (e.g., outlines, concept maps, design diagrams), but rarely are they called upon to organize the information themselves. This is a challenge for students - seeing the "big picture" can be tough. With practice; however, their organizational skills can be more fully developed.

\section{Team}

Engineers do their work in teams. Even individual work is directed at some larger, team-based project. Our students know this, and most undergraduate programs give students practice in working in groups. However, we wonder how much students realize that their teaming abilities and people skills are often more important than their technical expertise. Engineers work with people first and technology second.

\section{Write}

Engineers write. All our students take both technical and creative writing courses. Many programs have realized the limited utility of technical writing courses taught without connection to the engineering subject matter so that increasing numbers of engineering programs are making use of writing skills within engineering classes. This needs to continue and to increase still further. The most successful engineers are able to write well and efficiently. Every engineering course could have a significant and meaningful writing component.

\section{Speak}

Presentations are the preferred method of communication for engineers. Our profession relies on formal and informal PowerPoint-type presentations. Our students need to be knowledgeable and practiced in the substance and style of effective presentations. Much of this may be somewhat foreign to most engineers; engineering professional can be notoriously poor presenters. Luckily, there are resources that treat presentations as effective communication [7]. We can include this position in each engineering course.

\section{POSTSCRIPT}

It is possible and valuable to organize the essence of engineering practice and performance in five "positions" akin to the positions of the feet in classical ballet. When faced with a particularly challenging engineering problem, engineering professionals rely on one or more of these positions. It is important for our students to develop each of these equally in our courses.

\section{REFERENCES}

[1] Minden, E., G., The Ballet Companion, Fireside, 2005, pp. 85-103.

[2] London, B., and Deyo, L., "WIP - Classical Ballet Structure and Practice Applied to Engineering Class Sessions", $34^{\text {th }}$ ASEE/IEEE FIE Conference, October 2004, pp. F1E-20 - F1E-21.

[3] London, B., and Deyo, L., "The Ballet Model in Engineering Classes What Works, What Doesn't, and What's New", $35^{\text {th }}$ ASEE/IEEE FIE Conference, October 200, pp. T2C-27 - T2C-32.

[4] www.nycballet.com/programs/whatisballet.html, May 14, 2006.

[5] Accreditation Board for Engineering \& Technology (ABET), http://www.abet.org/forms.shtml, May 14, 2006.

[6] Frye, E., Engineering Problem Solving for Mathematics, Science, and Technology Education, 1997, Trustees of Dartmouth College; available online at http://engineering.dartmouth.edu/teps/book.html.

[7] Alley, M., The Craft of Scientific Presentations, Springer, 2005. 